\title{
Monitoring and Trust in Virtual Teams
}

\author{
Lionel P. Robert Jr. \\ School of Information \\ University of Michigan \\ 4417 North Quad, 105 South State St., Ann Arbor, MI 48109 \\ 1probert@umich.edu
}

\begin{abstract}
This study was conducted to determine whether monitoring moderated the impact of trust on the project performance of 57 virtual teams. Two sources of monitoring were examined: internal monitoring done by team members and external monitoring done by someone outside of the team. Two types of trust were also examined: affective-based trust, or trust based on emotion; and cognitive trust, or trust based on competency. Results indicate that when internal monitoring was high, affective trust was associated with increases in performance. However, affective trust was associated with decreases in performance when external monitoring was high. Both types of monitoring reduced the strong positive relationship between cognitive trust and the performance of virtual teams. Results of this study provide new insights about monitoring and trust in virtual teams and inform both theory and design.
\end{abstract}

\section{Author Keywords}

Monitoring; trust; virtual teams.

\section{ACM Classification Keywords}

H.3.5; H.4.3; K.6.0

\section{General Terms}

Human factors; design; measurement.

\section{INTRODUCTION}

Monitoring is a type of control that can have important implications for trust, a vital component of better team performance in virtual teams [18]. Research on virtual teams indicates that monitoring can facilitate or hinder the development of trust $[16,21,59]$. However, we know very little about how monitoring or being monitored might hinder or support trust in the facilitation of better team performance in virtual teams [63].

In this paper, we define monitoring as the act of observing the actions of others to determine whether they comply with

\footnotetext{
Permission to make digital or hard copies of all or part of this work for personal or classroom use is granted without fee provided that copies are not made or distributed for profit or commercial advantage and that copies bear this notice and the full citation on the first page. Copyrights for components of this work owned by others than ACM must be honored. Abstracting with credit is permitted. To copy otherwise, or republish, to post on servers or to redistribute to lists, requires prior specific permission and/or a fee. Request permissions from Permissions@acm.org.

$C S C W^{\prime} 16$, February 27-March 02, 2016, San Francisco, CA, USA

(C) 2016 ACM. ISBN 978-1-4503-3592-8/16/02 \$15.00

DOI: http://dx.doi.org/10.1145/2818048.2820076
}

a predefined set of behaviors [21,59]. Trust is defined as an individual's willingness to become vulnerable to the actions of others with the expectation that others will follow through on their commitments [50,51]. Monitoring and trust are two important topics in the Computer Supported Cooperative Work (CSCW) community. For example, CSCW scholars have studied how awareness systems can help geographically dispersed teams compensate for their lack of a shared context $[5,9,17,28,35]$. This is often done by allowing team members to monitor the actions of their teammates by providing real-time detailed status updates or audit trails [24,71,72,79]. These awareness systems allow teammates to see what was done, how it was done and who did it.

However, the ability to monitor others is not without drawbacks, and this problem has not gone unnoticed in the (CSCW)/Human Computer Interaction (HCI) community. Although many studies have lauded the benefits of awareness systems that entail monitoring (for a review see [70]), other CSCW/HCI scholars have identified the problems that can arise as a result of monitoring through awareness systems [30]. Specifically, Olson and Olson [56] warned that monitoring could be problematic for trust. Despite this, no follow-up research has explicitly articulated or examined the conditions under which monitoring may or may not present a problem for trust in such teams.

Consequently, our lack of knowledge about how monitoring might influence the effects of trust presents both a theoretical problem for social scientists and a conundrum for designers of collaborative systems. To address this problem, we examined whether monitoring moderates the impact of trust on the performance of virtual teams. Our goal is to understand when monitoring undermines or strengthens the impact of trust in virtual teams. To accomplish this, we put forth a research model asserting that the relationship between trust and performance in virtual teams depends on the type of trust as well as the source of monitoring.

This study differentiates between cognitive trust rooted in ability and affective trust derived from strong interpersonal emotional connections [39]. Whereas trust in general can be described as the willingness of someone to be dependent on the actions of others, differences in cognitive and affective trust determine the foundation of this vulnerability [52]. For example, allowing someone to perform a task on your 
behalf because you believe that person can accomplish the task is an example of cognitive trust. However, allowing someone to perform a task on your behalf because you are emotionally close to that person would be an example of affective trust.

This study also differentiates between internal monitoring done by team members and external monitoring done by an outside evaluator. Typically, monitoring involves assigning tasks and duties to team members and observing when and whether such tasks are carried out. One common example of monitoring is the request for status updates about work currently being performed [19]. Another type of monitoring is giving comments or feedback on the work previously performed [11]. Requests for status updates by team members to determine whether their teammates are following through on their commitments is an example of internal monitoring [16]. For instance, team members may ask other members whether they have completed their tasks or why their tasks were not completed on time [19]. Status updates required by someone outside of the team are an example of external monitoring. For example, a supervisor may inquire about whether a job has been completed or why it has not $[11,32]$. Supervisors may also ask why their instructions were or were not followed [33]. These are all examples of monitoring.

To empirically test this model we conducted a study involving 57 virtual teams. Results of our study indicated that both internal and external monitoring moderated the impacts of cognitive and affective trust on the performance of virtual teams. Both internal and external monitoring decreased the otherwise positive relationship between cognitive trust and performance. However, the findings related to affective trust were much more complex.

The goal of this study is to provide theoretical insights that can be used to inform the design of collaborative systems. To that end, this study contributes to theory in the following ways: First, it identifies why monitoring might be beneficial or detrimental to the performance of virtual teams. Second, it highlights the important role that monitoring has on the effects of trust in virtual teams. Third, it demonstrates why the source of monitoring and the type of trust are important to understanding the relationship between monitoring and trust in virtual teams. In addition, the results of this study may have implications for the design of collaborative systems. By identifying the boundary conditions under which monitoring could be helpful or harmful, the results of this study have the potential to inform designers about when collaborative systems should provide monitoring.

\section{BACKGROUND}

Monitoring is normally done by specifying a predefined set of behaviors [21,59]. This predefined set of behaviors is typically an agreed-upon or well-understood set of expectations [42]. These expectations help to ensure that an individual's behavior is directed at achieving a desired outcome [21]. Because monitoring seeks to alter an individual's behavior it is often referred to as a type of behavioral control [42,49]. Behavioral controls are considered effective when individuals exhibit the intended pre-specified behaviors $[21,43,59]$.

Monitoring of teams has been found to be a particularly popular and beneficial type of control $[19,45]$. Monitoring increases both cooperation and coordination in teams $[13,14]$. Individuals are more likely to cooperative and fulfill obligations to the team when others are observing their actions; as such, monitoring encourages team members to fulfill their commitments to the team [20,45]. Monitoring allows team members to better coordinate their actions with one another [18]. By monitoring the actions of others, team members know when their input to the task process is needed and when to step in on behalf of others $[29,48]$. Therefore, the ability to coordinate work among teammates is a particularly important element for successful teamwork.

Monitoring can be done internally by team members or externally by outside evaluators [47]. Internal monitoring typically involves team members setting expectations and observing whether members meet or fail to meet these expectations [21]. External monitoring is done by someone who is not a member of the team but normally evaluates the team performance [7]. Evaluators normally seek to determine whether the team and its members are following through with their commitments $[32,42]$. Both types of monitoring have been shown to motivate members to follow through on their commitments and allow team members to coordinate their efforts $[31,41]$.

Much of the research on monitoring in virtual teams has been directed at understanding the impact of internal monitoring on trust. Trust in teams is fostered when a teammate engages in actions that conform to the positive expectations of other team members $[60,65]$. Similarly to monitoring, trust has been linked to performance gains by promoting cooperation and coordination within teams. For example, trust has been found to promote knowledge sharing and using, which facilitated better decision-making in both face-to-face and virtual teams [66]. Trust has also been found to increase performance in collocated teams performing a building design task [23] and increased performance in organizational teams engaged in planning and problem-solving [26].

There have been mixed findings on the relationship between internal monitoring and trust in virtual teams. Several studies have found that internal monitoring increases the salience of members' behavior (i.e. draws more attention to it) $[21,59]$. Increases in the salience of behavior are normally measured by what team members focus on or remember from previous interactions [21,59]. In one study, internal monitoring was negatively related to trust in virtual teams because it increased the salience of reneging - instances of members failing to fulfill their commitment [59]. In another study, internal monitoring 
increased the salience of all behavior, both reneging and commitment fulfilling [21]. But individuals were also predisposed to see what they wanted to see based on their disposition to trust [21]. So, internal monitoring increased the salience of others' behavior but individuals high in disposition to trust interpreted that behavior more positively than individuals low in disposition to trust. However, another study found that monitoring was positively related to trust in virtual teams because it encourages compliance and provides a record of it [16].

Despite the importance of and the progress made toward understanding the relationship between internal monitoring and trust in virtual teams, several areas of study remain largely unexplored. First, we know very little about how monitoring might influence the effects of trust. Yet it is very likely that the effects of monitoring and trust overlap at some point during a team's tenure. Second, although we have made progress on understanding the relationships between internal monitoring and trust, no such progress has been made on understanding the relationship between external monitoring and trust. Because external monitoring is performed by someone outside of the team it is likely to have different implications for the impacts of trust on performance. Finally, previous studies have not differentiated between types of trust. Research on the relationship between employees and supervisors has found that cognitive-based trust (developed by assessing someone's ability) and affective-based trust (derived from emotional bonds) can produce completely different outcomes [16]. This paper seeks to advance our understanding in all three of these areas. Figure 1 presents the research model.

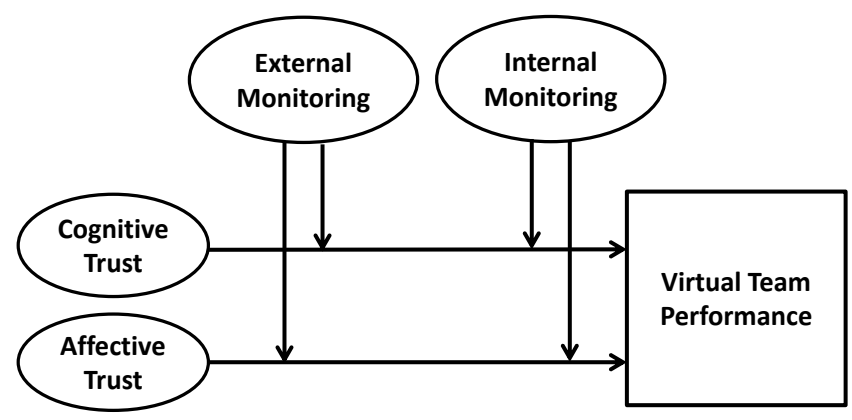

Figure 1. Research Model

CONCEPTUALIZING VIRTUAL TEAM PERFORMANCE

Teams are often formed with the purpose of accomplishing a set of interrelated and interdependent objectives. Typically team performance is conceptualized in a way that captures how well the teams meet or exceed these objectives. For example, teams assembled to complete a project are routinely judged by how well their evaluator believes their project was done $[7,45,55,64]$. Similarly, in this paper team performance is conceptualized as project performance judged by how well the team's evaluator, in this case their instructor, believes their project was done.

\section{RESEARCH MODEL}

Prior literature has found that cognitive-based trust promotes cooperation and coordination [38,51]. In general, team members are much more willing to cooperate with and coordinate with individuals they believe are competent [22]. This is, in part, because they believe their efforts are more likely to lead to a successful outcome when they engage in social exchanges with others they believe can and will follow through on their commitments [50]. Specifically, this belief that others will follow on their commitments encourages all team members to put forward more effort. An example of this was found by De Jong and Elfring [19]. They studied teams in a tax department of a multinational consultancy firm. Their study found that team trust based competency was positively associated with team members' effort and ultimately performance. Team performance was measured by the team's supervisor's rating of how well the team accomplished its tasks.

Cognitive-based trust can also lead to better coordination. Individuals have limited cognitive or attentional resources. Trusting others allows team members to focus on their own tasks without worrying whether others will follow through [51]. This also allows them to act with certainty under the assumption that other team members will follow through, which also promotes coordination in teams [73]. For example, Kanawattanachai and Yoo [40] examined 38 virtual teams of master of business administration students. The researchers found that cognitive trust was associated with increases in coordination. Coordination was measured as the degree to which virtual teams believed their teammates understood, carefully considered and acted on the actions taken by other team members. This measure of coordination was associated with increases in virtual team performance. Performance was determined by how well the team performed on its class project.

The benefits of internal monitoring should suppress the effects of cognitive trust because they work to promote cooperation and coordination in much the same way as cognitive trust. Internal monitoring can increase the effort put forth by individuals. Team members are more inclined to exert effort when they believe others are watching $[2,38,45]$, which is one of the benefits associated with cognitive trust. The process of observing the actions of one's teammates requires both continued attention and contact among team members [21,67]. This continued attention and contact ensures that team members are kept aware of one another's activities [18]. Awareness of one another's activities allows team members to synchronize their actions [48,73]. For example, Marks and Panzer [48] found that when flight simulation teams observed what their teammates were doing, this acted as a feedback mechanism that improved coordination and led to better flight performance on the simulation. Contact, awareness and synchronization, facilitated through internal monitoring, all act as mechanisms to promote coordination and cooperation within teams $[45,62]$. 
The impacts of cognitive trust on team performance appear to be similar to the impacts of internal monitoring. As such, we would expect the impact of cognitive trust to be greatly diminished in the presence of high internal monitoring. Therefore, we would expect cognitive trust to be associated with increases in virtual team performance when the use of internal monitoring is low. However, when the use of internal monitoring is high, cognitive-based trust should have little impact on the performance of virtual teams.

H1: Cognitive trust has a strong positive relationship with team performance when internal monitoring is low but has little or no relationship with team performance when internal monitoring is high.

External monitoring should also moderate the relationship between cognitive-based trust and performance in much the same way as internal monitoring. Typically, external monitoring takes place when managers or supervisors observe the behavior of their employees $[42,43]$. Managers routinely inquire into what team members have or have not done [32,42]. These inquiries are done to ensure that team members are engaging in cooperative behaviors by fulfilling their commitments to the team [57]. Research supports this assertion and has found that when managers engage in monitoring, employees are more inclined to fulfill their commitments, which facilitates more cooperation and coordination [31,41]. For example, Carbonell and Rodriguez-Escudero [11] examined new product development teams. They measured external monitoring by asking team managers how much they engaged in activities like observing whether their teams achieved their goals or provided feedback to teams about their goal attainment. The authors found that external monitoring increased participation among team members and also reduced conflict and ambiguity over role assignments within the team, both of which are strong indicators of increases in cooperation and coordination.

These increases in cooperation and coordination through external monitoring can lead to better team performance. An example of the link between external monitoring and team performance was found by Henderson and Lee [33]. They studied 48 information systems design teams from 10 companies. The authors measured external monitoring by asking team members to indicate the degree to which their manager kept track of and provided feedback on their performance. The authors discovered that external monitoring was positively associated with team performance. Team performance was measured as the team supervisor's rating of how efficient and effective the teams were at meeting their goals.

Because external monitoring increases team performance in much the same way as cognitive trust, the impact of cognitive trust should diminish in the presence of external monitoring. As stated earlier, cognitive trust has also been linked to team performance by in part because cognitive trust facilitates cooperation and coordination by encouraging team members to fulfill their commitments to their team [50]. Therefore, when external monitoring is high, any impact from cognitive trust is less likely to provide additional improvements in cooperation and coordination over and above external monitoring.

H2: Cognitive trust has a strong positive relationship with team performance when external monitoring is low but has little or no effect on team performance when external monitoring is high.

Unlike cognitive trust, affective trust is not based on ability and competency [52]. Affective trust is often based on similarities between individuals [39]. It is often derived from personal relationships that develop outside of work [68]. Affective trust normally takes longer to develop in virtual teams than cognitive trust $[39,68]$. Cognitive trust can be very dynamic, increasing or decreasing based on whether an individual fulfills or fails to fulfill commitments [65]. Affective trust is more robust and can withstand more violations of trust by other team members; therefore it can often exist long after it should [74,75].

Affective trust also has several performance benefits. Virtual teams often fail to fully utilize the unique expertise of their members $[21,66,77]$. Team members are less likely to share information when they believe they will be belittled, ignored or seen as incompetent [25,66,78]. Affective trust represents a safe atmosphere where team members are comfortable sharing information with their teammates $[12,68]$. Virtual teams with a high level of affective trust have members who are more inclined to view their teammate's problem and their team's problem as their own problem [39,52]. Because of this, people in teams with high affective trust tend to take on additional roles on behalf of the team $[3,12,52]$. These individuals not only accomplish their own task but also assist teammates in accomplishing their tasks [52]. Such behavior in cooperative work settings has been associated with increases in performance $[40,51,52]$.

However, affective trust can have drawbacks. High levels of strong emotional trust have been associated with complacency [45]. Team members may assume the other members are holding up their end of the bargain when, in fact, some members are not. Virtual teams high in affective trust can also be more concerned about maintaining good relations between members [4,54]. As a result, when a team member fails to fulfill commitments, other team members are less willing to call out that member for poor performance [45]. This is particularly problematic for virtual teams high in affective trust. According to prior literature $[38,75,76]$, team members high in affective trust are less likely to be sensitive to reneging. This is because "emotions and affective attachments, in turn, can influence trust by increasing the 'feel' that another is trustworthy [38] and by positively biasing perceptions of trustworthiness, attributions, and motivations that are relevant to trust maintenance [75]" [76, p. 610]. As such, teams high in 
affective trust are more likely to allow individual members multiple chances to renege [52]. As a result, virtual teams high in affective trust are likely to sustain repeated violations of trust before action is taken.

Internal monitoring is likely to allow members to hold one another accountable without damaging intra-team relationships [16]. When virtual teams routinely engage in internal monitoring, members who have failed are less likely to take it personally when their lack of performance is highlighted. In turn, because their failure is highlighted by a routine team activity no one individual has to confront any particular team member. This helps virtual teams to maintain good interpersonal relationships while holding others accountable. Internal monitoring can also make a team member's repeated failures salient, increasing the likelihood of the team taking action to correct the problem $[18,45]$. At the same time, these virtual teams benefit from the openness and willingness of team members to share information and take on extra roles on behalf of the team.

H3: Affective trust has a strong positive relationship with team performance when internal monitoring is high but has a strong negative relationship with team performance when internal monitoring is low.

External monitoring is likely to have negative effects on virtual teams high in affective trust. Unlike internal monitoring, monitoring that originates from outside the team may be viewed as an unwanted intervention. Virtual teams with strong impersonal bonds can develop a shared identity [66]. External monitoring can be seen as a threat to this shared identity, a threat that violates the team's psychologically safe environment $[10,25]$. As a result, team members might be less likely to share unique and important information when they believe they are being monitored externally [25]. This can undermine an important benefit of affective-based trust for virtual teams.

External monitoring is also associated with detailed instructions that can force unwanted changes in team work processes. Several studies have linked external monitoring to detailed instructions [7, 61]. An example of the potential negative effects associated with detailed instructions was found by Bonner et al. [7]. They measured external monitoring by asking former team members whether their managers provided detailed instructions along with their monitoring activities. Project performance was measured by asking former team members how well their team met project performance objectives. They studied new product development teams and found that when managers gave detailed instructions to their teams, performance decreased.

Detailed instructions can be particularly problematic because teams with high emotional bonds often develop work assignments through consensus-building and prospective-taking $[7,10]$. This is done by accommodating each member's schedule or personal preference. These accommodations are less likely to occur when members are given specific instructions from external monitors on how work should be performed. When such consensus-building is replaced by hierarchical directives, team members are more likely to disengage. This explanation is often used to understand why outside interventions are sometimes associated with decreases in the amount of effort members contribute in teams with strong emotional bonds [72].

H4: Affective trust has a strong negative relationship with team performance when external monitoring is high but has a strong positive relationship with team performance when external monitoring is low.

\section{METHOD}

\section{Data Collection and Participants}

To test these hypotheses, we conducted a web-based survey of virtual teams. Data were collected from an online global campus designed to cater to the needs of current professional, full-time, employed students. Participants were enrolled in a human resource management online graduate program. The teams were considered to be virtual because all members were geographically dispersed and they communicated primarily through electronic communications [64,65]. Typically, individuals were randomly assigned to teams. However, the final decision was determined by the instructor. In fact, all decisions about team size, projects and scoring were made by each instructor, with no input from this paper's author(s). And none of the classes was taught by the author(s).

The participants' ages ranged from 26 to 62 years, with a mean of 37 years. Seventy-three percent of the participants were female. Participants had an average of 11.9 years of prior full-time work experience. A total of 214 individuals in 57 teams participated in the study. The size of the teams averaged 4 and ranged from 3 to 5 . The average team project lasted about 60 days. Participants took part in a team project as part of their course requirement and received extra credit for completing the survey. The team project accounted for $25 \%$ of the students' final grade.

\section{Virtual Platform}

All the teams had access to the same collaboration system. This system afforded the teams the opportunity to communicate through chat, email and video. The system allowed teams to monitor the action of their teammates. For example, users could set automatic reminders which informed the teams when assignments were coming due and who was responsible for accomplishing the work. Teams members also routinely employed the system to inquire about the status of individual assignments. The instructor also had full access to the system and could also monitor the team's progression or lack of it.

\section{Measurement}

The participants were assured their responses would be kept confidential. They were also informed that only the researcher(s) would see their responses, and their responses would in no way influence their grade. The survey 
consisted of 17 questions and took about 10-15 minutes to complete. All perceptual measures used a seven-point Likert scale.

Team measures were obtained by aggregating individual responses. To justify these aggregations individual team members needed some level of agreement or similarity in their response to answering questions regarding each construct. Intra-class correlation coefficient one - ICC(1) - is typically used to justify this aggregation by measuring the within-team agreement [6]. The logic holds that to justify the aggregation of individual responses to the team level, members within the same team should have responded similarly to the same items. ICC(1) is used to test this assumption by empirically verifying that a significant portion of the variance in responses is explained by team membership. For example, an ICC(1) of .10 indicates that $10 \%$ of the variance in responses is a result of team membership. In other words, we can predict $10 \%$ of the variance in an individual team member's response based on his or her team membership. Intra-class correlation coefficient two - ICC(2) - is normally used to assess the reliability of the construct at the team level [6]. Both were employed in this study.

\section{Control Variables}

We used several control variables to reduce the possibility of alternative explanations. We controlled for team tenure (amount time the team was together), team size, team grade point average, task interdependency and instructor. These control variables were chosen because they have been found to influence performance in studies of graduate teams, in particular those examining trust or monitoring, e.g., $[18,45,64]$.

\section{Independent Variables}

The items measuring the independent variables were taken from well-established prior literature, specifically the same literature base that motivated this study. This is also the literature base this study is designed to inform. Therefore, employing many of the same measures used in prior literature allows us to better situate our findings with those in the prior literature. Additionally, all measurement items used in this study were developed and validated by other researchers.

Items measuring affective trust should capture the extent to which members care for one another, while items measuring cognitive trust should quantify how much team members believe they can count on one another to get things done on their behalf. Items measuring these constructs are well represented by McAllister's [52] operationalization of both constructs. McAllister's [52] was one of the first papers to develop measurement items for each of these constructs, which have been used in many other studies, e.g., [26,37,39,68]. An example of an item measuring cognitive trust include "I know I can count on the other team members," while an example of affective trust included "I would have to say that we (my team) have made considerable emotional investments in our working relationship.

Items measuring monitoring should represent the degree to which someone observed and paid attention to the actions of others to ensure that they complied [33]. The internal and external monitoring items were taken from Henderson and Lee [33] and Crisp and Jarvenpaa [16]. Both papers capture the extent to which team members and evaluators observed and paid attention to the actions of team members. All the measurement items except for external monitoring were directly adopted. The items measuring external monitoring were adapted for the context. Specifically, the term "supervisor" was replaced with the term "instructor." In other words, the reference to external monitoring was the degree to which the course instructor engaged in monitoring. The items are listed in Table 1.

\section{Dependent Variable}

Team Performance Score and Team Project Description The project score given to the team by their instructor was used as the performance measure. Every team performed the same type of project; an assessment of an organization's current human resource system. The project required teams to evaluate an organization's hiring, training, evaluation and promotion practices. Every team had their own unique client. The project involved several phases. The first phase required teams to interview client representatives to assess their views on the system. The clients agreed to provide access to employees and formal documentation on their HR systems for the project. In the second phase, the teams created individual reports based on the data from their interviews and documentation analysis. In the third phase, teams then looked for patterns and trends across individual reports. In the final phase, the team produced a written report that outlined their assessment of the system. The team submitted one project to its instructor. Project performance scores ranged from 0 to 100 .

This course and the team project were selected for several reasons. First, the ages and work experience of the participants were similar to those of the organizational workers surveyed in past studies, e.g., [7,19,68]. This allows the research model to be empirically tested with older, more experienced individuals similar to workers in organizations. Second, the project score provided us with a standard objective measure that allowed performance across all teams to be compared. This is similar to other studies examining the implications of control and trust, e.g., $[16,36,39]$. Finally, the team project was both important and relevant to the participants' educational aspirations. The participants were enrolled in a human resource (HR) graduate degree program and the team project represented an application of their current knowledge on an HR-related project. As such, the team project was seen as an appropriate representation of the team's success. 


\begin{tabular}{|c|c|c|c|c|c|c|c|c|c|}
\hline & $\begin{array}{c}\text { Affective } \\
\text { Based } \\
\text { Trust } \\
\end{array}$ & $\begin{array}{c}\text { Cognitive } \\
\text { Based } \\
\text { Trust } \\
\end{array}$ & $\begin{array}{c}\text { External } \\
\text { Monitoring }\end{array}$ & $\begin{array}{c}\text { Internal } \\
\text { Monitoring }\end{array}$ & Size & $\begin{array}{c}\text { Task } \\
\text { Interdependency }\end{array}$ & Team GPA & Tenure & Performance \\
\hline Mean & 4.28 & 5.10 & 3.55 & 4.83 & 3.77 & 4.87 & 3.36 & 60.00 & 86.5 \\
\hline Median & 4.33 & 5.33 & 3.50 & 5.00 & 4.00 & 5.10 & 3.40 & 59.00 & 87 \\
\hline Mode & 4.67 & 5.50 & 3.00 & 5.00 & 4.00 & 4.00 & 2.60 & 55.00 & 85 \\
\hline Std. Deviation & 0.95 & 0.86 & 1.07 & 1.04 & 0.70 & 0.70 & 0.35 & 15.80 & 8.5 \\
\hline Variance & 0.90 & 0.74 & 1.14 & 1.08 & 0.49 & 0.49 & 0.12 & 249.64 & 72.25 \\
\hline Range & 4.80 & 4.90 & 5.50 & 5.70 & 3.00 & 3.22 & 1.45 & 75.00 & 33.00 \\
\hline
\end{tabular}

Table 1. Descriptive Statistics

\section{RESULTS}

To validate the measurement model we first examined the construct reliabilities. Construct reliabilities are summarized in Table 2. All construct reliabilities are at the acceptable threshold of .70 or above. Discriminant and convergent validity of the constructs was assessed in three ways. First, convergent and discriminant validity were assessed by examining the average variance shared (AVE) along the diagonals of a correlation matrix. The AVE represents how much of the latent construct's variance is captured by the items used to measure it. AVE scores at or above .5 are an indication of convergent validity [27]. This means that the measurement items being used captured at least half of the variance associated with that latent construct. As seen in Table 2, the AVE scores were all at or above .5, indicating adequate convergent validity [27].

Discriminant validity was assessed by determining whether the AVE of a construct was higher than its correlation with other constructs. The logic behind this test is that the items measuring a construct should represent more of that construct's variance than other items measuring other constructs. As seen in Table 2, the AVE scores of all constructs were larger than their corresponding row and column correlations, indicating adequate discriminant validity [27].

Second, discriminant and convergent validity were assessed through an exploratory factor analysis (EFA). As shown in Table 1, all items loaded at .7 or above on their corresponding construct and only one item had a crossloading of .4 or higher. We then assessed the psychometric properties of the perceptual measures and then the appropriateness of the measurement model for cognitive trust, affective trust, and external and internal behavioral control.

Finally, a confirmatory factor analysis (CFA) at the team level of analysis was performed. CFA is similar to EFA, with additional restrictions. A CFA imposes a structure on the data that presupposes not only what is related but what is also not related [34]. In other words, the CFA predicts that items measuring the construct should be related to the construct and items not measuring the construct should not be related to the construct.

The CFA imposes a structure on what should be related and what should not be related and compares it to the structure of the actual data. The degree to which the proposed structure matches the actual structure of the data determines the fit between the two. High fit or similarity between the two means that the measurement model is valid. The prominent fit index used to measure fit or misfit is the comparative fit index (CFI) [53]. Values of the CFI range from 0 , indicating no fit, to 1 , indicating a perfect fit. Because of the small team-level sample size and the number of indicators in the measurement model, we conducted the CFA using an item-parceling procedure outlined by Landis et al. [44]. Another prominent fit measure is the standardized root-mean-square residual (SRMR), which measures the average standardized residual per degree of freedom [34]. SRMR is a standardized measure of the discrepancy between the proposed model and the actual data. Values for SRMR range from 0 to 1 . Both measures are used to complement each other [34,53]. CFI values $\geq .95$ and SRMR values $\leq .08$ are considered to be an indication of a good fit [34].

The chi-square values were also reported to provide a means for comparing the relative fit of the models. Using the covariance matrix, 2-factor and 4-factor solutions were modeled. The initial 2-factor model, which modeled internal and external monitoring as one latent construct and both cognitive and affective trust as another latent construct, showed poor fit to the data $(\chi 2=6.72, \mathrm{df}=19, \mathrm{p}$ $<.05 ; \mathrm{CFI}=.68$; SRMR $=.14)$. The 4-factor model, which modeled internal and external control as well as cognitive and affective trust as separate latent constructs showed a good fit to the data $(\chi 2=1.8, \mathrm{df}=14, \mathrm{p}<.05 ; \mathrm{CFI}=.97$; SRMR $=.04)$. Paths representing the loading of each indicator were all significant and above .8 on its latent factor. The results suggest that this 4 -factor model fit the data well, with all fit indices meeting acceptable levels. Overall, both tests taken together provide support by discriminant and convergent validity of our measure model. 
I can talk freely to my team about difficulties I am having at work and know that my team will want to listen. If I share my problems with my team, I know s(he) would respond constructively and caringly.

I would have to say that we (my team) have made considerable emotional investments in our working relationship. We trust each other a lot in my team.

I know I can count on the other team members.

The other team members know they can count on me.

I trust all of the other team members.

Our instructor paid attention to how this team's performance stands.

Our instructor monitored our actions.

Our instructor paid attention to what people do on this team.

Our instructor monitored what members did to make sure they comply.

We paid attention to how this team's performance stands.

My team monitored the actions of its members.

We paid attention to what people do on this team.

Affective Trust Cognitive Trust

My team monitored what members do to make sure they comply.

Table 2. Factor Loadings

$\begin{array}{llll}.86 & .27 & .12 & .17 \\ . \mathbf{8 8} & .44 & .14 & .25 \\ . \mathbf{8 0} & .12 & .20 & .30 \\ .25 & .75 & .30 & .08 \\ .01 & . \mathbf{8 1} & .21 & .14 \\ .26 & .71 & .04 & .05 \\ .01 & .84 & .22 & .07 \\ .01 & .10 & \mathbf{. 8 8} & .11 \\ .13 & -.10 & \mathbf{. 8 5} & .14 \\ .10 & .20 & .84 & .23 \\ .03 & .07 & \mathbf{. 8 1} & .21 \\ .06 & .24 & .26 & \mathbf{. 8 2} \\ .13 & .21 & .30 & . \mathbf{8 2} \\ .15 & .20 & .23 & \mathbf{. 9 2} \\ .11 & .13 & .25 & \mathbf{. 9 2}\end{array}$

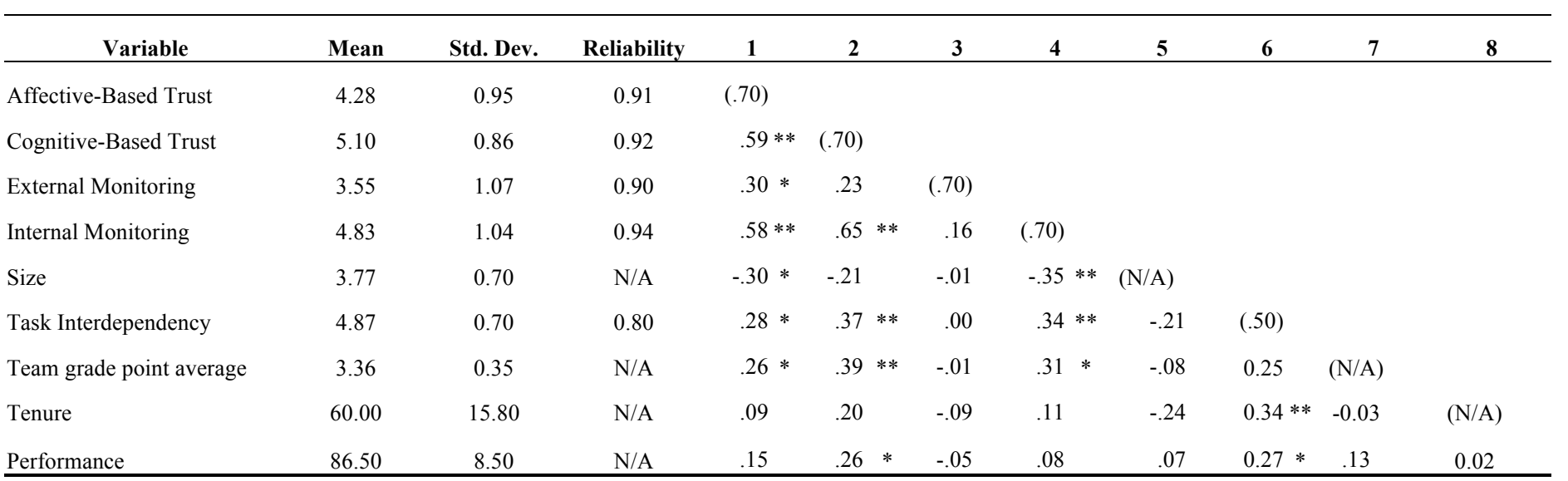

Notes: 1. Average Variance Extracted (AVE) in on the diagonal.

2. Significance of correlations: ${ }^{*} \mathrm{p}<.05 ; * * \mathrm{p}<.01$

3. $\mathrm{N}=57$ 
To determine whether it was appropriate to aggregate individual data to the team level, the ICC values for the aggregated constructs were derived from a one-way analysis of variance [6]. The random effects ANOVA-based F-statistic for each scale was significant at $p<0.05$. Scores were as follows: external control, $\operatorname{ICC}(1)=.44, \operatorname{ICC}(2)=$ .76; internal control, $\operatorname{ICC}(1)=.43, \operatorname{ICC}(2)=.75$; cognitive trust, $\operatorname{ICC}(1)=.36, \operatorname{ICC}(2)=.70$; affective trust, $\operatorname{ICC}(1)=$ $.37, \operatorname{ICC}(2)=.70$; and task interdependency, $\operatorname{ICC}(1)=.24$, $\operatorname{ICC}(2)=.56$. All $\operatorname{ICC}(1)$ and $\operatorname{ICC}(2)$ scores were at or above the recommended levels for a field study [6].

Hierarchical regression analysis was used to test the proposed model. Hierarchical regression analysis uses ordinarily least squared (OLS) regression to empirically test regression models that are nested. This allows regression models to be compared with one another as additional variables are added. In particular, comparisons are often done between models with or without moderation effects. This is done to determine whether the addition of moderation effects significantly increases the variance explained in the dependent variable.

The research model was also tested with partial least squares and the results were similar. All continuous variables were standardized, as suggested by Aiken and West [1], in order to reduce multicollinearity. The results are shown in Table 3. Model 1 shows the effects of the controls on the dependent variable. Model 2 shows the direct effects of cognitive and affective trust, and external and internal control. Model 3 includes the interaction effects. The control variables explained $19 \%$ of the variance and were non-significant $\left(\mathrm{F}_{6,50}=1.94, \mathrm{p}>.05\right)$. Model 2, the main effects model, explained $28 \%$ of the variance and was significant $\left(\mathrm{F}_{10,46}=2.16, \mathrm{p}<.05\right)$. Model 3, which included the interactions effects, explained $54.5 \%$ of the variance and was significant $\left(\mathrm{F}_{14,42}=3.55, \mathrm{p}>.001\right)$. The addition of the interaction effects increased the variance explained by $26 \%(\mathrm{~F}=2.5, \mathrm{p}>.001)$. In addition, the moderation effects were plotted to facilitate their interpretation. High and low levels of each variable involved in the interaction were represented by one standard deviation above and below the mean [1].

$\mathrm{H} 1$, internal monitoring moderates the impact of cognitive trust on team performance, was supported. The interaction between internal monitoring and cognitive trust on team performance was significant $(\beta=-3.8 ; p<.01)$. The relationship is plotted in Figure 2 to further facilitate the interpretation of the interaction.

$\mathrm{H} 2$, external monitoring moderates the impact of cognitive trust on team performance, was supported. The interaction between external monitoring and cognitive trust on team performance was significant $(\beta=-3.00 ; \mathrm{p}<.05)$. The plotted interaction is displayed in Figure 3.

\begin{tabular}{|c|c|c|c|}
\hline \multirow[b]{2}{*}{ Independent Variables } & \multicolumn{3}{|c|}{ Team Performance } \\
\hline & Model 1 & Model 2 & Model 3 \\
\hline \multicolumn{4}{|l|}{ Control Variables } \\
\hline Team Ability (GPA) & 0.56 & -0.11 & 0.88 \\
\hline Team Tenure & -0.41 & -1.20 & -2.30 \\
\hline Team Size & 0.33 & 0.22 & 0.17 \\
\hline Task Interdependency & $2.74 *$ & $2.50 *$ & $2.50 *$ \\
\hline Instructor & $5.30 *$ & $7.30 * *$ & $7.40 * *$ \\
\hline R Square & $19.0 \%$ & & \\
\hline $\mathrm{F}$ & 1.93 & & \\
\hline \multicolumn{4}{|l|}{ Main Effects } \\
\hline Affective Trust & & -0.05 & 0.50 \\
\hline Cognitive Trust & & 2.40 & 2.80 \\
\hline External Monitoring & & $-2.54 *$ & $-2.50 *$ \\
\hline Internal Monitoring & & -0.04 & -1.80 \\
\hline R Square & & $28.0 \%$ & \\
\hline $\mathrm{F}$ & & 1.81 & \\
\hline \multicolumn{4}{|l|}{ Interactions Effects } \\
\hline \multicolumn{4}{|l|}{ Affective Trust X Internal } \\
\hline Monitoring & & & $7.85 * *$ \\
\hline \multicolumn{4}{|l|}{ Affective Trust X External } \\
\hline Monitoring & & & $-2.30 *$ \\
\hline \multicolumn{4}{|l|}{ Cognitive Trust X Internal } \\
\hline Monitoring & & & $-3.80 *$ \\
\hline \multicolumn{4}{|l|}{ Cognitive Trust X External } \\
\hline Monitoring & & & $-3.00 *$ \\
\hline R Square & & & $50.6 \%$ \\
\hline $\mathrm{F}$ & & & $2.21 *$ \\
\hline Change in $\mathrm{R}$ Square & & & $22.6 \%$ \\
\hline Significant Level & & & $2.5 *$ \\
\hline \multicolumn{4}{|c|}{$\begin{array}{l}\mathrm{n}=57 \text { Unstandardized Regression coefficients are reported. All } \\
\text { continuous variables were standardized } \\
* \mathrm{p}<.05 ; * * \mathrm{p}<.01\end{array}$} \\
\hline
\end{tabular}

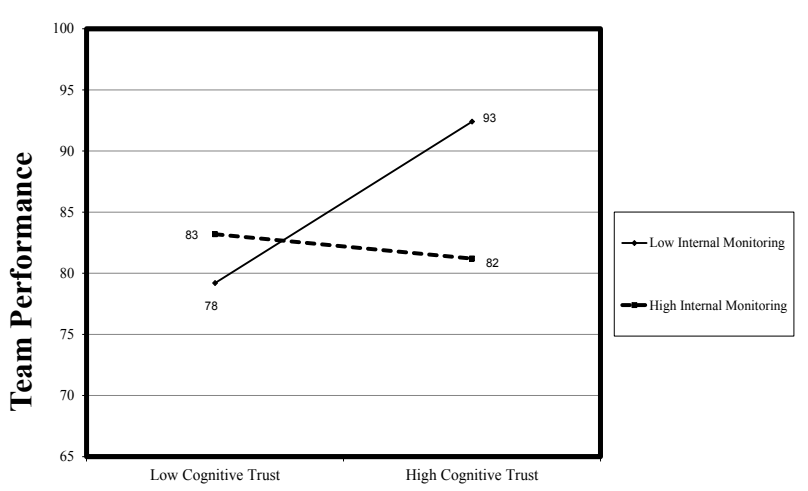

Figure 2. Interaction between Internal Monitoring and Cognitive Trust 


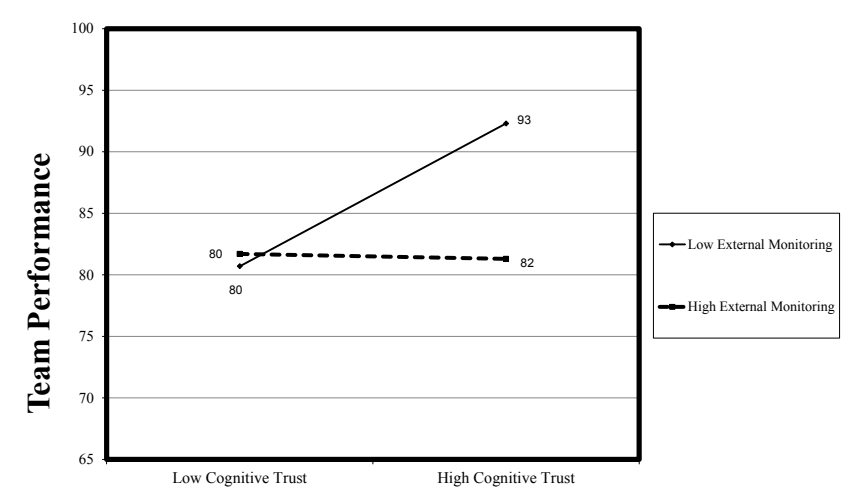

Figure 3. Interaction between External Monitoring and Cognitive Trust

H3, internal monitoring moderates the impact of affective trust on team performance, was supported. The interaction between internal monitoring and affective trust on team performance was significant $(\beta=7.85 ; p<.001)$. Figure 4 is the plotted interaction of the relationship.

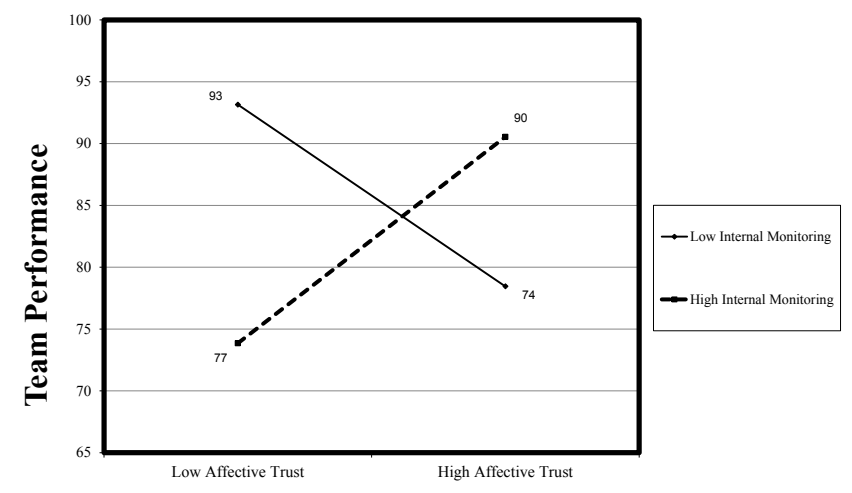

Figure 4. Interaction between Internal Monitoring and Affective Trust

H4, external monitoring moderates the impact of affective trust on team performance, was supported. The interaction between external monitoring and affective trust on team performance was significant $(\beta=-2.3 ; \mathrm{p}<.05)$. The relationship is displayed in Figure 5.

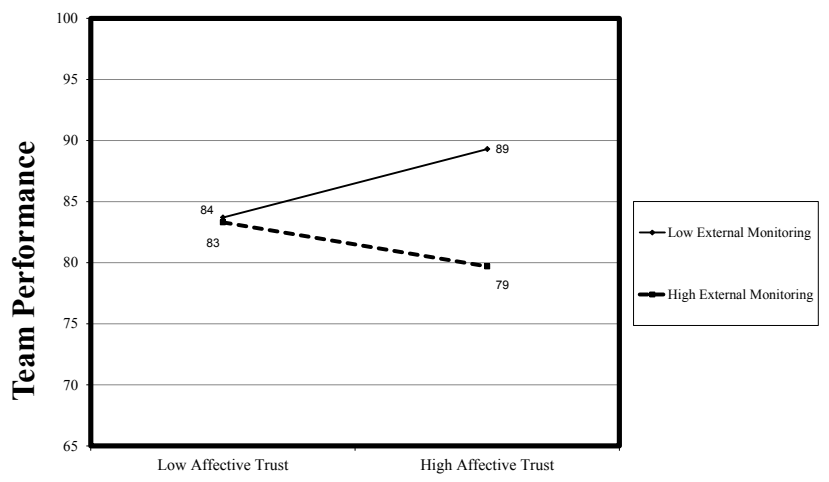

Figure 5. Interaction between External Monitoring and Affective Trust

\section{Summary of the Results}

Results of this study clearly show that both internal and external monitoring decrease the strong positive relationship between cognitive trust and performance. For example, virtual teams high in cognitive trust that did not engage in internal monitoring or were not externally monitored had an average performance score of just above 93 (see Figures 2 and 3). Virtual teams high in cognitive trust that did engage in internal monitoring or were externally monitored had an average performance score of 82 (see Figures 2 and 3). This 11-point difference was greater than one standard deviation $(+/-8)$ in team performance.

Results of this study highlight the important differences between internal and external monitoring when it comes to affective trust. Affective trust had a strong negative relationship with performance when virtual teams did not engage in internal monitoring but a strong positive relationship with performance when virtual teams did engage in internal monitoring (see Figure 4). The opposite appeared to be true for external monitoring. Affective trust had a strong negative relationship with performance when virtual teams were subjected to external monitoring but a strong positive relationship with performance when they were not (see Figure 5).

Overall, this study shows that the effects of trust on the performance of virtual teams are heavily dependent on monitoring. Trust in virtual teams has been found to have a positive relationship $[39,58]$ or in some cases no relationship $[3,36]$ with performance. This quandary parallels the findings by scholars who study trust in collocated teams (see [23]). In many cases scholars have turned their attention to understanding when and under what circumstances trust facilitates better teamwork [18]. Results of this study identify monitoring as a key contingency variable that determines when trust leads to better performance. The current literature on this topic has not taken into account the possible moderation role of monitoring, let alone how the source of monitoring might matter. Therefore, this study contributes to the literature by highlighting when trust might facilitate, reduce or have no relationship with performance in virtual teams.

\section{DISCUSSION}

This study provides new insights into how monitoring can facilitate or hinder team performance by altering the effects of trust in virtual teams. Research on monitoring and trust in virtual teams has examined whether monitoring can facilitate or hinder the growth of trust [21]. The implicit or explicit assumption is that monitoring can impact team performance by increasing or decreasing trust. However, as the results of this study have shown, monitoring can also alter the impacts of trust on team performance. Yet we know very little about how monitoring might alter the effects of trust. As we have shown in this study, when monitoring occurs the results can range from 
complementing to undermining the effects of trust. Thus, this goes beyond existing knowledge and contributes to our understanding of when monitoring and trust might lead to better or worse performance in virtual teams. In the following sections, we discuss the limitations associated with the study followed by the implications of theory, design and practice. Then the conclusions are presented.

\section{Limitations}

Like all cross-sectional research this study has several limitations. First, monitoring and trust were captured using self-reported items. Self-reported items can be biased. However, by using an objective measure of team performance rather than a team self-reported measure, this study reduces the impact of such bias. Second, the design implications are based on a projection of the study's results. However, this study did not examine virtual teams using awareness systems. Future research should manipulate the types of awareness systems used by virtual teams. The results from such research would provide stronger recommendations and insight for design. Finally, future research should seek to understand how culture may or may not change the impact of monitoring. Individuals from different cultures may react differently to monitoring or being monitored.

\section{Design Implications}

Implications for design can be derived from the findings. However, these findings are based on the assumption that awareness systems allow for internal and external monitoring of virtual teams. To that extent, these recommendations should be interpreted as implications related to when, whether and how awareness systems should be designed to support internal and external monitoring.

At first glance design recommendations regarding awareness systems that allow internal monitoring seem paradoxical. On one hand internal monitoring can be problematic by reducing the performance of virtual teams by suppressing the positive effects of cognitive trust. On the other hand, internal monitoring can help increase performance by allowing virtual teams to take advantage of their affective trust. One way to accommodate the effects of internal monitoring on both types of trust is to design a dynamic awareness system that automatically increases and decreases the ability of virtual teams to engage in internal monitoring based on whether the virtual team's members are fulfilling their commitments. For example, in teams with high cognitive trust the system could discourage monitoring by making it difficult to accomplish. On the other hand, in virtual teams low in cognitive trust the system could suggest and encourage virtual teams to engage in monitoring.

Dynamic awareness systems that automatically increase and decrease internal monitoring could provide two benefits. First, they could allow teams to fully benefit from their cognitive trust without the need of internal monitoring. We would expect the need for monitoring to decrease as team members fulfilled their commitments and we would also expect cognitive trust to be high in such teams. As a result, as members fulfilled their commitments cognitive trust would increase while internal monitoring by dynamic awareness systems would decrease. This implication for design is derived from the finding related to hypothesis 1.

Second, dynamic awareness systems might also benefit virtual teams high in affective trust. Affective trust is likely to lead to decreases in performance when virtual team members are not engaged in internal monitoring because of repeated reneging $[38,75]$. This is because in virtual teams high in affective trust, team performance is likely to be diminished for a longer time period from the problems associated with reneging while waiting for team members to call out other members [75]. However, this problem can be avoided with the help of dynamic awareness systems. When reneging occurs dynamic awareness systems can automatically increase internal monitoring. This, in turn, is likely to draw attention to the reneging. By dynamically adjusting the level of internal monitoring by the occurrences of reneging, these systems can ensure that teams with affective trust also engage in internal monitoring. This may reduce the possibility that affective trust will be associated with decreases in performance.

Finally, based on the findings associated with hypotheses 2 and 4, external monitoring seems to provide no benefit to virtual teams. These findings suggest that the ability of awareness systems to provide external monitoring may be problematic. This leaves designers of such systems with three alternatives. One, simply do not allow evaluators the ability to monitor the virtual teams they supervise. Another alternative is to provide much less detail or timely information about the actions of virtual team members. For example, awareness systems could provide warning alerts to managers once the team has missed several deadlines rather than providing real-time information on who failed to fulfill a commitment. Another alternative is to have supervisors monitor virtual teams without the knowledge of the members. However, this is problematic on a couple levels. First, it might be considered unethical. Second, it is likely that as soon as an evaluator took action based on information obtained from monitoring, team members would immediately become aware that they were being monitored anyway. Either way, designers might have to rethink the value associated with external monitoring.

\section{Implications for Theory}

This paper advances research on the relationship between monitoring and trust in virtual teams. We moved beyond the topic of whether monitoring increases or decreases trust to examining how monitoring determines when trust leads to better performance in virtual teams. Research on the relationship between monitoring and trust has not explored such implications or even begun to explore how the source of monitoring or the type of trust impacts these 
relationships. This study demonstrates that both the source of monitoring and the type of trust should be taken into account to better understand how monitoring alters the effects of trust in virtual teams. This, in turn, might begin to shift the discussion from whether monitoring facilitates or hinders the development of trust to how monitoring influences the impact of trust.

\section{Monitoring and Cognitive Trust}

Many scholars studying the tradeoffs between control and trust in teams and other collaborative activities have proposed that trust is the better coordination and cooperation mechanism $[13,46,52]$. This is, in part, because trust does not require the additional cost in terms of the attention and effort required by internal monitoring. Trust, as many scholars have asserted, can lead to comparable or better team performance without the additional attention and effort needed by teams to implement controls $[8,14,15]$. But if this were true, we would expect to see a different moderation effect between internal monitoring and cognitive trust than we see with external monitoring and cognitive trust. External monitoring does not require teams to exert the same level of effort or attention as internal monitoring.

However, the moderation effects between both types of monitoring and cognitive trust were very similar. This suggests that the negative effect of monitoring on cognitive trust is not related solely to the effort and attention needed to implement such controls. This calls for a revision of our understanding of trust and control in teams. One explanation is that when monitoring is implemented, internally or externally, team members lose their initiative and only take action when told to do so. This lack of initiative may explain why both internal and external monitoring seems to have a similar moderation effect on cognitive trust. Future studies should be conducted to examine this proposition.

\section{External Monitoring and Trust}

Unlike the relationship between internal monitoring and trust, we know very little about the relationship between external monitoring and trust in virtual teams. The literature on control and trust in virtual teams has focused exclusively on internal monitoring. Yet, it is very likely that organizations and supervisors exert some type of control on virtual teams. Results of this study demonstrate the theoretical similarities (i.e. moderation with cognitive trust) and differences (i.e. moderation with affective trust) between external monitoring and internal monitoring. As such this study contributes to theory by delineating when and how the source of monitoring matters. Therefore, considering the results of this study, more research is needed to fully understand how the source of control influences its impact on virtual teams. Studies should be conducted to further explore the potential role of external monitoring in virtual teams.

\section{CONCLUSION}

Monitoring and trust are two mechanisms used to promote cooperation and coordination in virtual teams, yet their relationship is poorly understood. This study demonstrates that in certain situations monitoring can undermine the positive impacts of trust on team performance. However, in other situations monitoring complements the impact of trust. Taken together, the results of this study highlight the nuanced and complex relationship between trust and monitoring in virtual teams.

\section{ACKNOWLEDGMENTS}

I would like to thank Mark Ackerman and Paul

Resnick for their useful feedback.

\section{REFERENCES}

1. Leona S. Aiken and Stephen G. West. 1991. Multiple Regression: Testing and Interpreting Interactions. Sage, Newbury Park, CA, 132-136.

2. Omar Alnuaimi, Lionel Robert and Likoebe Maruping. 2009. Social loafing in brainstorming CMC teams: The role of moral disengagement. In Proceedings of the Hawaii International Conference on System Sciences (HICSS '09), 1-9.

3. Benoit A. Aubert and Barbara L. Kelsey. 2003. Further understanding of trust and performance in virtual teams. Small Gr Res 34, 5: 575-618.

4. Francis Bidault and Alessio Castello. 2012. Why too much trust is death to innovation. Image.

5. Jeremy Birnholtz and Steven Ibara. 2012. Tracking changes in collaborative writing: edits, visibility and group maintenance. In Proceedings of the ACM 2012 conference on Computer Supported Cooperative Work, ACM, 809-818.

6. Paul D. Bliese. 2000. Within-group agreement, nonindependence, and reliability: Implications for data aggregation and analysis. In Multilevel Theory, Research, and Methods in Organizations, Katherine J. Klein and Steve W. J. Kozlowski (eds.) Jossey-Bass, San Francisco, CA, 349-381.

7. Joseph M. Bonner, Robert W. Ruekert, and Orville C. Walker. 2002. Upper management control of new product development projects and project performance. J Prod Innovat Manag 19, 3: 233-245.

8. Philip Bromiley and Larry L. Cummings. 1995. Transactions costs in organizations with trust. Res Negot O 5, 219-250.

9. Lisanne Brons, Tjerk de Greef, and Rick van der Kleij. 2010. The influence of an activity awareness display on distributed multi-team systems. Proceedings of the 28th Annual European Conference on Cognitive Ergonomics, ACM, 335-336.

10. David F. Caldwell and Charles A. O'Reilly. 2003. The Determinants of team-based innovation in 
organizations the role of social influence. Small Gr Res 34, 4: 497-517.

11. Pilar Carbonell and A. I. Rodriguez-Escudero 2013. Management control, role expectations and job satisfaction of new product development teams: the moderating effect of participative decision making. Ind Market Manag 42, 2: 248-254.

12. Sanjib Chowdhury. 2005. The role of affect- and cognition-based trust in complex knowledge sharing. $J$ Manage Issues 17, 3: 310-326.

13. Ana Cristina Costa and Katinka Bijlsma-Frankema. 2007. Trust and control interrelations: New perspectives on the trust - control nexus. Group Organ Manage 32, 4: 392-406.

14. Ana Cristina Costa, Katinka Bijlsma-Frankema, Bart de Jong. 2009. The role of social capital on trust development and dynamics: Implications for cooperation, monitoring and team performance. Soc Sci Inform 48, 2: 199-228.

15. W.E. Douglas Creed and Raymond E. Miles. 1996. Trust in organizations: A conceptual framework. Trust in Organizations: Frontiers of Theory and Research, Roderick M. Kramer and Tom R. Tyler (eds.). Sage, Thousand Oaks, CA, 16-38.

16. C. Brad Crisp and Sirkka L. Jarvenpaa. 2013. Swift trust in global virtual teams: Trusting beliefs and normative actions. J Pers Psychol 12, 1: 45.

17. Laura Dabbish and Robert Kraut. 2008. Research noteawareness displays and social motivation for coordinating communication. Inform Syst Res 19, 2: 221-238.

18. Bart A. De Jong and Kurt T. Dirks. 2012. Beyond shared perceptions of trust and monitoring in teams: Implications of asymmetry and dissensus. J Appl Psychol 97, 2, 391.

19. Bart A. De Jong and Tom Elfring. 2010. How does trust affect the performance of ongoing teams? The mediating role of reflexivity, monitoring, and effort. Acad Manag J 53, 3: 535-549.

20. Bart A. De Jong, Katinka M. Bijlsma-Frankema, Laura B. Cardinal. 2014. Stronger Than the sum of its parts? The performance implications of peer control combinations in teams. Organ Sci 25, 6: 1703-1721.

21. Alan R. Dennis, Lionel P. Robert Jr., Aaron M. Curtis, Stacy T. Kowalczyk, Bryan K. Hasty. 2012. Research note -- Trust is in the eye of the beholder: A vignette study of postevent behavioral controls' effects on individual trust in virtual teams. Inform Syst Res 23, 2: 546-558.

22. Kurt T. Dirks. 1999. The effects of interpersonal trust on work group performance. J Appl Psychol 84, 3: 445.
23. Kurt T. Dirks and Donald L. Ferrin. 2002. Trust in leadership: Meta-analytic findings and implications for research and practice. J Appl Psychol 87, 4: 611.

24. Paul Dourish and Victoria Bellotti. 1992. Awareness and coordination in shared workspaces. Proceedings of the 1992 ACM conference on Computer-Supported Cooperative Work, ACM, 107-114.

25. Amy Edmondson. 1999. Psychological safety and learning behavior in work teams. Admin Sci Quart 44, 2: $350-383$.

26. Ferda Erdem and Janset Ozen. 2003. Cognitive and affective dimensions of trust in developing team performance. Team Perform Manag Int J 9, 5/6: 131135.

27. Claes Fornell and David F. Larcker. 1981. Evaluating structural equation models with unobservable variables and measurement error. J Marketing Res 18, 1: 39-50.

28. Susan R. Fussell and Robert M. Krauss. 1992. Coordination of knowledge in communication: Effects of speakers' assumptions about what others know. $J$ Pers Soc Psychol 62, 3: 378.

29. Susan R. Fussell, Robert E. Kraut, F. Javier Lerch, William L. Scherlis, Matthew M. McNally, Jonathan J. Cadiz. 1998. Coordination, overload and team performance: Effects of team communication strategies. Proceedings of the 1998 ACM conference on Computer Supported Cooperative Work. ACM, 275-284.

30. Patrice Godefroid, James D. Herbsleb, Lalita Jategaonkar Jagadeesany, Du Li. 2000. Ensuring privacy in presence awareness: an automated verification approach. Proceedings of the 2000 ACM conference on Computer Supported Cooperative Work, ACM, 59-68.

31. Paul S. Goodman, Elizabeth C. Ravlin, Marshall Schminke. 1987. Understanding groups in organizations. Res Organ Behav 9, 121-173

32. Anandasivam Gopal and Sanjay Gosain. 2010. Research note -- The role of organizational controls and boundary spanning in software development outsourcing: Implications for project performance. Inform Syst Res 21, 4: 960-982.

33. John C. Henderson and Lee Soonchul. 1992. Managing I/S design teams: a control theories perspective. Manag Sci 38, 6: 757-777.

34. Li-Tze Hu and Peter M. Bentler. 1999. Cutoff criteria for fit indexes in covariance structure analysis: Conventional criteria versus new alternatives. Struct Equ Model 6, 1: 1-55.

35. Chyng-Yang Jang, Charles Steinfield, Ben Pfaff. 2002. Virtual team awareness and groupware support: an evaluation of the TeamSCOPE system. Int J HumComput St 56, 1: 109-126. 
36. Sirkka L. Jarvenpaa, Thomas R. Shaw, D. Sandy Staples. 2004. Toward contextualized theories of trust: The role of trust in global virtual teams. Inform Syst Res 15, 3: 250-267.

37. Devon Johnson and Kent Grayson. 2005. Cognitive and affective trust in service relationships. J Bus Res 58, 4, 500-507.

38. Gareth R. Jones and Jennifer M. George. 1998. The experience and evolution of trust: Implications for cooperation and teamwork. Acad Manag Rev 23, 3: 531-546.

39. Prasert Kanawattanachai and Youngjin Yoo. 2002. Dynamic nature of trust in virtual teams. J Strategic Inform Syst 11, 3: 187-213.

40. Prasert Kanawattanachai and Youngjin Yoo. 2007. The impact of knowledge coordination on virtual team performance over time. MIS Quart 31, 4: 783-808.

41. Steven Kerr and John M. Jermier. 1978. Substitutes for leadership: Their meaning and measurement. Organ Behav Hum Perf 22, 3: 375-403.

42. Laurie J. Kirsch. 1996. The management of complex tasks in organizations: Controlling the systems development process. Organ Sci 7, 1: 1-21.

43. Laurie J. Kirsch, Dong-Gil Ko, Mark H. Haney. 2010. Investigating the antecedents of team-based clan control: Adding social capital as a predictor. Organ Sci 21, 2: 469-489.

44. Ronald S. Landis, Daniel J. Beal, Paul E. Tesluk. 2000. A comparison of approaches to forming composite measures in structural equation models. Organ Res Methods 3, 2: 186-207.

45. Claus W. Langfred. 2004. Too much of a good thing? Negative effects of high trust and individual autonomy in self-managing teams. Acad Manage J 47, 3: 385399.

46. Roy J. Lewicki, Daniel J. McAllister, and Robert J. Bies. 1998. Trust and distrust: New relationships and realities. Acad Manage Rev 23, 3: 438-458.

47. Misty L. Loughry and Henry L. Tosi. 2008. Performance implications of peer monitoring. Organ Sci 19, 6: 876-890.

48. Michelle A. Marks and Frederick J. Panzer. 2004. The influence of team monitoring on team processes and performance. Hum Perform 17, 1: 25-41.

49. Likoebe M. Maruping, Viswanath Venkatesh, Ritu Agarwal. 2009. A control theory perspective on agile methodology use and changing user requirements. Inform Syst Res 20, 3: 377-399.

50. Roger C. Mayer, James H. Davis, F. David Schoorman. 1995. An integrative model of organizational trust. Acad Manage Rev 20, 3: 709-734.
51. Roger C. Mayer and Mark B. Gavin. 2005. Trust in management and performance: Who minds the shop while the employees watch the boss? Acad Manage $J$ 48, 5: 874-888.

52. Daniel J. McAllister. 1995. Affect-and cognition-based trust as foundations for interpersonal cooperation in organizations. Acad Manage Journal 38, 1: 24-59.

53. Gina J. Medsker, Larry J. Williams, Patricia J. Holahan. 1994. A review of current practices for evaluating causal models in organizational behavior and human resources management research. J Manage 20, 2: 439-464.

54. F. Xavier Molina-Morales and M. Teresa MartínezFernández. 2009. Too much love in the neighborhood can hurt: How an excess of intensity and trust in relationships may produce negative effects on firms. Strategic Manage J 30, 9: 1013-1023.

55. Sean A. Munson, Karina Kervin, Lionel P. Robert Jr. 2014. Monitoring email to indicate project team performance and mutual attraction. Proceedings of the 2014 conference on Computer Supported Cooperative Work \& Social Computing. ACM, 542-549.

56. Gary M. Olson and Judith S. Olson. 2003. Humancomputer interaction: Psychological aspects of the human use of computing. Ann Rev Psychol 54, 1: 491516.

57. William G. Ouchi and Mary Ann Maguire. 1975. Organizational control: Two functions. Admin Sci Quart 20, 4: 559-569.

58. David L. Paul and Reuben R. McDaniel Jr. 2004. A field study of the effect of interpersonal trust on virtual collaborative relationship performance. MIS Quart 28, 2: 183-227.

59. Gabriele Piccoli and Blake Ives. 2003. Trust and the unintended effects of behavior control in virtual teams. MIS Quart 27, 3: 365-395.

60. Gabriele Piccoli, Anne Powell, Blake Ives. 2004. Virtual teams: Team control structure, work processes, and team effectiveness. Inform Tech People 17, 4: 359-379.

61. Jarno Poskela and Miia Martinsuo. 2009. Management control and strategic renewal in the front end of innovation. J Prod Innovat Manag 26, 6: 671-684.

62. Ramón Rico, Miriam Sánchez-Manzanares, Francisco Gil, and Cristina Gibson. 2008. Team implicit coordination processes: A team knowledge-based approach. Acad Manag Rev 33, 1: 163-184.

63. Lionel P. Robert Jr. 2013. Trust and control in virtual teams: Unraveling the impact of team awareness systems in virtual teams. CSCW Workshop 2013 on Trust in Virtual Teams: Theory. 
64. Lionel P. Robert. 2013. A multi-level analysis of the impact of shared leadership in diverse virtual teams. Proceedings of the 2013 conference on Computer Supported Cooperative Work (CSCW). ACM, 363374.

65. Lionel P. Robert, Alan R. Dennis, Yu-Ting Caisy Hung. 2009. Individual swift trust and knowledgebased trust in face-to-face and virtual team members. $J$ Manage Inform Syst 26, 2: 241-279.

66. Lionel P. Robert, Alan R. Dennis, Manju K. Ahuja. 2008. Social capital and knowledge integration in digitally enabled teams. Inform Syst Res 19, 3: 314334.

67. Charles F. Sabel. 1993. Constitutional ordering in historical context. In Games in Hierarchies and Networks: Analytical and Empirical Approaches to the Study of Governance Institutions, Fritz W. Scharpf (ed.). Westview Press, 65-123.

68. John Schaubroeck, Simon S.K. Lam, Ann Chunyan Peng. 2011. Cognition-based and affect-based trust as mediators of leader behavior influences on team performance. J Appl Psychol 96, 4: 863.

69. F. David Schoorman, Roger C. Mayer, James H. Davis. 2007. An integrative model of organizational trust: Past, present, and future. Acad Manage Rev 32, 2: 344-354.

70. Igor Steinmacher, Ana Paula Chaves, Marco Aurelio Gerosa. 2010. Awareness support in global software development: a systematic review based on the $3 \mathrm{C}$ collaboration model. In Collaboration and Technology, Gwendolyn Kolfschoten, Thomas Herrmann, Stephan Lukosch (eds.). Springer, Berlin, 185-201.

71. Igor Steinmacher, Ana Paula Chaves, Marco Aurélio Gerosa. 2013. Awareness support in distributed software development: A systematic review and mapping of the literature. Computer Supported Cooperative Work (CSCW) 22, 2-3: 113-158.

72. Kristy L. Towry. 2003. Control in a teamwork environment - The impact of social ties on the effectiveness of mutual monitoring contracts. Account Rev 78, 4: 1069-1095.

73. Paul W.L. Vlaar, Frans A.J. Van den Bosch, Henk W. Volberda. 2007. On the evolution of trust, distrust, and formal coordination and control in interorganizational relationships toward an integrative framework. Group Organ Manage 32, 4: 407-428.

74. Sheila Simsarian Webber. 2008. Development of cognitive and affective trust in teams a longitudinal study. Small Gr Res 39, 6: 746-769.

75. Michele Williams. 2001. In whom we trust: Group membership as an affective context for trust development. Acad Manage Rev 26, 3: 377-396.

76. Michele Williams. 2007. Building genuine trust through interpersonal emotion management: A threat regulation model of trust and collaboration across boundaries. Acad Manage Rev 32, 2: 595-621.

77. Jaime. B. Windeler, Likoebe M. Maruping, Lionel P. Robert \& Cindy K. Riemenschneider. 2015. E-profiles, Conflict, and Shared Understanding in Distributed Teams. J of the Ass. for Inform Syst, 16,7: 608-645.

78. Gwen M. Wittenbaum, Andrea B. Hollingshead, Paul B. Paulus et al. 2004. The functional perspective as a lens for understanding groups. Small Gr Res 35, 1: 1743.

79. Koji Yatani, Darren Gergle, Khai Truong. 2012. Investigating effects of visual and tactile feedback on spatial coordination in collaborative handheld systems. Proceedings of the ACM 2012 conference on Computer Supported Cooperative Work, ACM, 661670. 